\title{
More Widely Spaced Comb-Like Polymers of Which Teeth Appear on Every 15, 19, 23, and 26 Repeating Main-Chain Atoms
}

\author{
Tadamichi Hirabayashi, Kazuo Kasabou, and Kenji YoKota \\ Department of Materials Science and Engineering, \\ Nagoya Institute of Technology, \\ Gokiso-cho, Showa-ku, Nagoya 466, Japan
}

(Received April 4, 1988)

\begin{abstract}
A series of comb-like polymers, poly(2-alkyltrimethylene alkanedioates), were synthesized from 2-dodecyl-, 2-tetradecyl-, 2-hexadecyl-, or 2-octadecylpropanediol-1,3 and sebacoyl, tetradecanedioyl, octadecanedioyl or henicosanedioyl chloride. A differential scanning calorimetry study on the crystallization of these more widely spaced comb-like polymers showed that crystallization involves the main-chains as well as side-chains.
\end{abstract}

KEY WORDS Comb-Like Polymer / Widely Spaced Comb-Like Polymer / 2-Alkylpropanediol-1,3 / Diacid Chloride / Polyester / Crystallization /

In our previous papers, ${ }^{1-3}$ we synthesized several widely spaced comb-like polymers with teeth (long alkyl groups $\mathrm{R}$ in the next structural formulas) appearing on every $4,{ }^{3} 6,{ }^{1}$ and $11-15^{2}$ repeating main-chain atoms.<smiles>[R]OC(=O)[CH]C#CCC</smiles>

alternating styreneacrylic ester copolymers

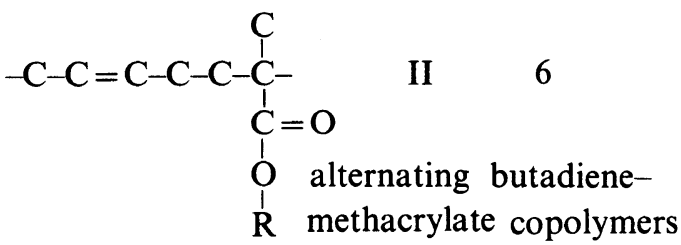<smiles>[R]OC(=O)C(C)(C)CCCCCC</smiles>

III 6 periodic ethyleneethylene-methacrylate copolymers<smiles>[Y]C(=O)CC(=O)OCC([R])COC</smiles>
poly(2-hexadecyltrimethylene alkanedioates)

The long alkyl side-chains $\mathrm{R}$ in these widely spaced comb-like polymers crystallize as in conventional comb-like polymers $\mathrm{V}$,<smiles>[R][X]C(C)C</smiles><smiles>[V][V]</smiles>

$\mathrm{X}$ denotes a connecting functional group

in spite of the wide spaces between them.

In the present paper, we studied the crystallization of more widely spaced comb-like 
polymers with teeth appearing on every 15 , 19,23 , and 26 repeating main-chain atoms. Structural formula IV was chosen for this study. In such more widely spaced comb-like polymers, crystallization involves the mainchains as well as side-chains.

\section{EXPERIMENTAL}

\section{Monomers}

2-Dodecyl-, 2-tetradecyl-, and 2-octadecylpropanediol-1,3 were synthesized by starting from the corresponding alkyl bromide and diethyl malonate by the same method described for 2-hexadecylpropanediol-1,3 in a previous paper. ${ }^{2}$ Pure diols were obtained by recrystallizing from benzene and identified by IR and ${ }^{1} \mathrm{H}$ NMR spectra, which were essentially identical with the spectra reported for the hexadecyldiol. An example is given in Figure 1 for 2-dodecylpropanediol-1,3. Overall yield, $\mathrm{mp}$, and elemental analyses are as follows. 2Dodecylpropanediol-1,3: $58 \%, 72.8-74.4^{\circ} \mathrm{C}$. Calcd for $\mathrm{C}_{15} \mathrm{H}_{32} \mathrm{O}_{2}$ : C, $73.71 \%$; H, $13.20 \%$. Found: C, $73.55 \%$; H, 12.88\%. 2-Tetradecylpropanediol-1,3: $43 \%, 80.1-80.9^{\circ} \mathrm{C}$. Calcd for $\mathrm{C}_{17} \mathrm{H}_{36} \mathrm{O}_{2}$ : C, $74.94 \%$; H, 13.32\%. Found: C, $74.76 \%$; H, $12.97 \%$. 2-Octadecylpropanediol-1,3: $56 \%, \quad 88.2-90.1^{\circ} \mathrm{C}$. Calcd for $\mathrm{C}_{21} \mathrm{H}_{44} \mathrm{O}_{2}$ : C, $76.76 \%$; H, 13.50\%. Found: C, $76.14 \%$; H, $12.94 \%$.

Tetradecanedioic acid was a commercially available EP reagent. Octadecanedioic or henicosanedioic acid was synthesized by starting from 1-morpholino-1-cyclohexene ${ }^{4}$ and adipoyl chloride or sebacoyl chloride according to Hünig et al. ${ }^{5}$ Octadecanedioic acid: yield $38 \%, \mathrm{mp} 129.8-131.8^{\circ} \mathrm{C}$ [lit. ${ }^{6} 128^{\circ} \mathrm{C}$ ]. Calcd
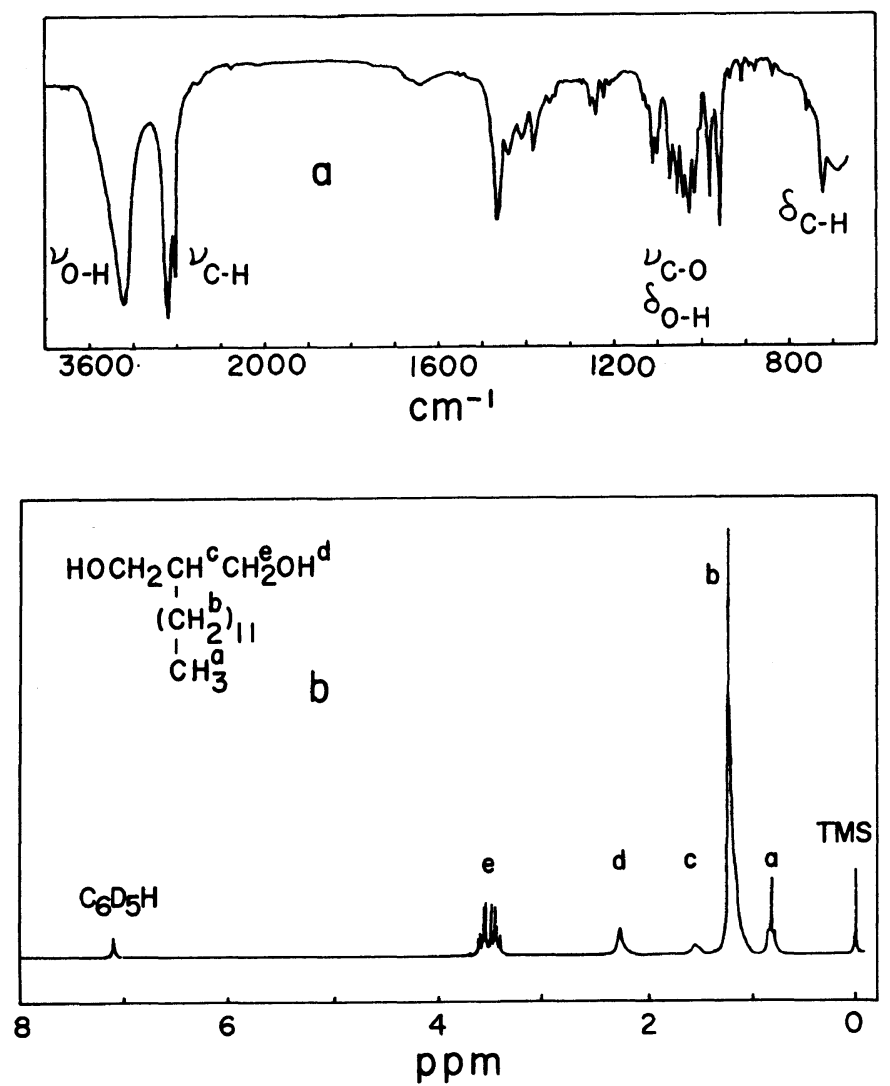

Figure 1. (a) IR as liquid film and (b) ${ }^{1} \mathrm{H}$ NMR spectra in $\mathrm{C}_{6} \mathrm{D}_{6}$ of 2-dodecylpropanediol-1,3. 
for $\mathrm{C}_{18} \mathrm{H}_{34} \mathrm{O}_{4}$ : C, $68.75 \% ; \mathrm{H}, 10.90 \%$. Found: C, $68.99 \%$; H, $11.31 \%$. Henicosanedioic acid: yield $73 \%$, mp $119.0-120.8^{\circ} \mathrm{C}$ [lit. ${ }^{6} 121.8-$ $123.2^{\circ} \mathrm{C}$. Calcd for $\mathrm{C}_{21} \mathrm{H}_{40} \mathrm{O}_{4}: \mathrm{C}, 70.74 \% ; \mathrm{H}$, $11.31 \%$. Found: C, $70.92 \%$; H, $11.95 \%$. Both products showed IR absorptions of diacid.

Sebacoyl chloride, prepared in the previous paper, ${ }^{2}$ was redistilled before use. Tetradecanedioylchloride, octadecanedioyl chloride, and henicosanedioyl chloride were prepared from diacid and thionyl chloride. Excess thionyl chloride was removed from the reaction mixture under vacuum, and the residual diacid chloride was used for polymerization without isolation.

\section{Polymerization}

A mixture of diacid chloride $(0.5-1 \mathrm{~g})$, diol (accurately equimolar to the diacid chloride), and toluene $(2-5 \mathrm{ml})$ was gently heated at $130^{\circ} \mathrm{C}$ for 1 day and then poured into methanol. The collected solid was once reprecipitated by benzene-methanol. Then it was stirred with hot ethanol for $10 \mathrm{~min}$ and the supernatant was discarded while hot. This extraction procedure was repeated five times to remove unreacted monomer and lower molecular weight part of polymer. The product polymer was freeze-dried under vacuum and subjected to measurements.

\section{Measurements}

Gel-permeation chromatography (GPC) for polymer-molecular weight determination and differential scanning calorimetry (DSC) for thermal analysis were the same as in previous papers. $^{1-3}$
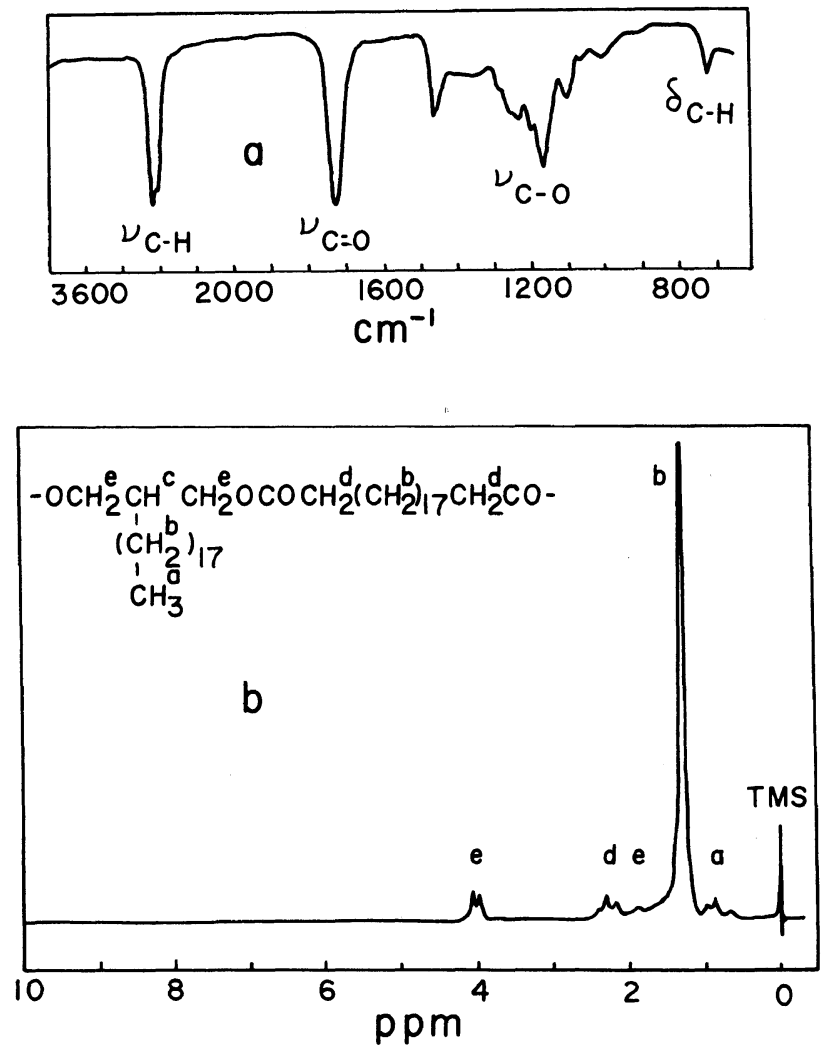

Figure 2. (a) IR as liquid film and (b) ${ }^{1} \mathrm{H}$ NMR spectra in $\mathrm{CDCl}_{3}$ of 2-octadecyltrimethylene henicosanedioate). 


\section{RESULTS AND DISCUSSION}

Table I summarizes yield, molecular weight and degree of polymerization for each of poly(2-alkyltrimethylene alkanedioate) samples. Structure IV was identified by IR and ${ }^{1} \mathrm{H}$ NMR spectra. An example is given in Figure 2 for poly(2-octadecyltrimethylene henicosanedioate). Even though each of the highest molecular weight samples obtained among several polymerization experiments is shown in Table I, the molecular weights or degrees of polymerization are rather low due to condensation. Based on the previous results $^{2}$ on the thermal analyses of poly(2hexadecyltrimethylene adipate) of various molecular weights, the samples in Table I with sufficiently high molecular weights were considered to warrant discussion.

Figure 3 shows all DSC traces for more widely spaced comb-like polymers. The polymer symbol $\mathrm{C}_{\mathrm{p}}-\mathrm{B}_{\mathrm{q}}$ (B means "Branching")

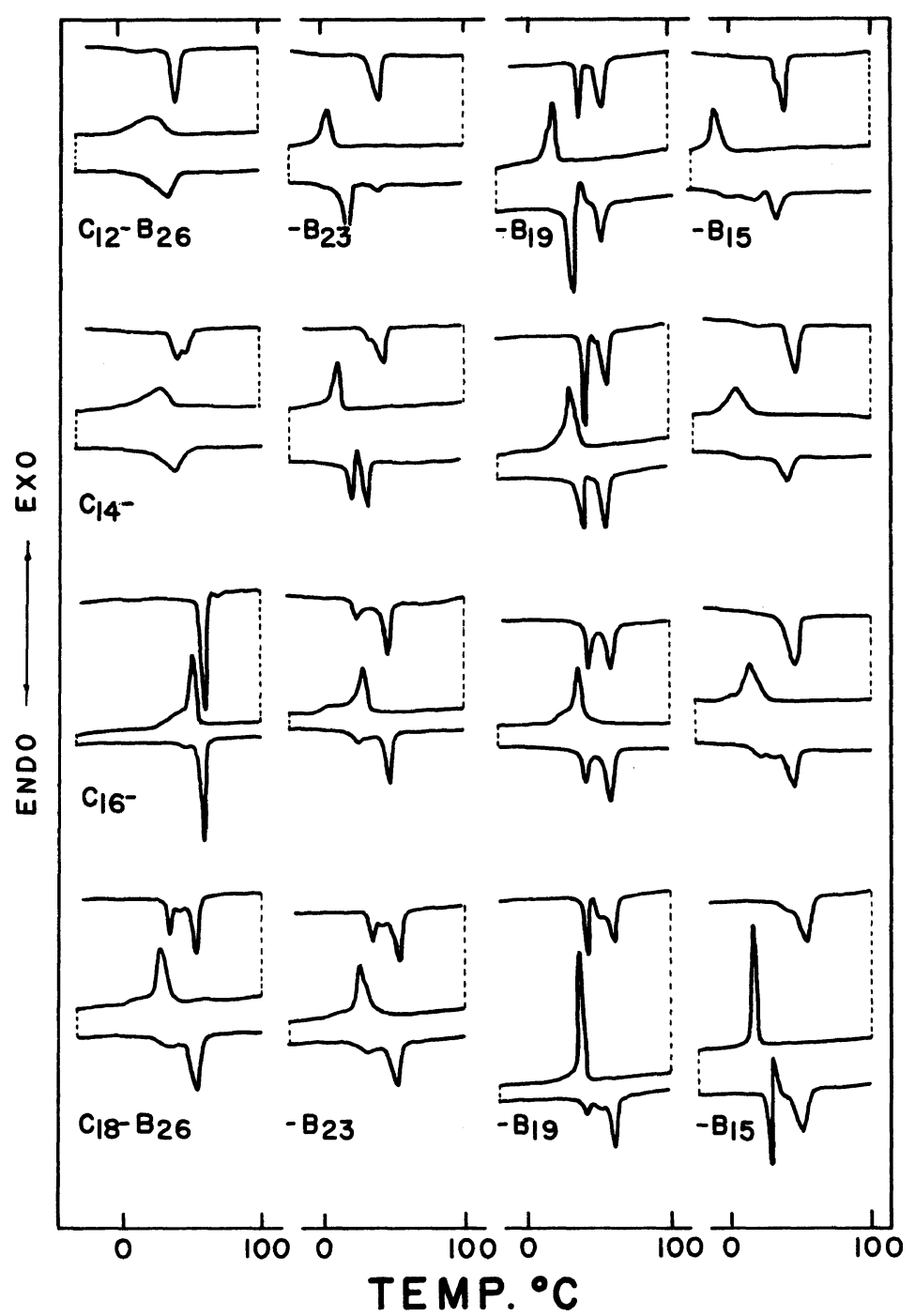

Figure 3. DSC traces for poly(2-alkyltrimethylene alkanedioates). For the polymer symbol, see the text. 
Table I. Sample characteristics of poly(2-alkyltrimethylene alkanedioates) prepared

\begin{tabular}{|c|c|c|c|}
\hline Polymer $^{a}$ & $\frac{\text { Yield }^{\mathrm{b}}}{\%}$ & $\begin{array}{l}\text { Molecular } \\
\text { weight }^{c}\end{array}$ & $\begin{array}{c}\text { Degree of } \\
\text { polymerization }\end{array}$ \\
\hline $\mathrm{C}_{12}-\mathrm{B}_{15}$ & 60 & 18000 & 43.8 \\
\hline$C_{14}-B_{15}$ & 66 & 13800 & 31.5 \\
\hline$C_{16}-B_{15}$ & 67 & 10800 & 23.1 \\
\hline $\mathrm{C}_{18}-\mathrm{B}_{15}$ & 42 & 22000 & 44.5 \\
\hline$C_{12}-B_{19}$ & 60 & 14500 & 31.1 \\
\hline $\mathrm{C}_{14}-\mathrm{B}_{19}$ & 69 & 18500 & 37.4 \\
\hline$C_{16}-B_{19}$ & 53 & 15000 & 28.7 \\
\hline $\mathrm{C}_{18}-\mathrm{B}_{19}$ & 53 & 15500 & 28.1 \\
\hline $\mathrm{C}_{12}-\mathrm{B}_{23}$ & 23 & 10900 & 20.8 \\
\hline $\mathrm{C}_{14}-\mathrm{B}_{23}$ & 18 & 11000 & 20.0 \\
\hline $\mathrm{C}_{16}-\mathrm{B}_{23}$ & 19 & 10500 & 18.1 \\
\hline$C_{18}-B_{23}$ & 40 & 9200 & 15.2 \\
\hline $\mathrm{C}_{12}-\mathrm{B}_{26}$ & 34 & 16000 & 28.3 \\
\hline $\mathrm{C}_{14}-\mathrm{B}_{26}$ & 32 & 14000 & 28.3 \\
\hline $\mathrm{C}_{16}-\mathrm{B}_{26}$ & 34 & 17000 & 27.4 \\
\hline$C_{18}-B_{26}$ & 16 & 11000 & 16.9 \\
\hline \multicolumn{4}{|c|}{$\begin{array}{l}\text { a For the polymer symbol, see the text. } \\
\text { b For the polymerization conditions and work up, see } \\
\text { the text. } \\
\text { c From GPC peak top with reference to polystyrene } \\
\text { standards. }\end{array}$} \\
\hline
\end{tabular}

denotes that the polymer has a long alkyl sidechain of $p$ carbons and its side chain appears on each $q$ main-chain atom. Here $q$ is given by $n+7, n$ being methylene numbers of the diacid unit in IV. Since we chose sebacic, tetradecanedioic, octadecanedioic, or henicosanedioic acid as the diacid unit, $q$ is $15,19,23$, or 26 , respectively. Carbon number $p$ is $12,14,16$, or 18. About $7 \mathrm{mg}$ of polymer sample as hot ethanol-extracted and dried were first heated from -100 to $+100^{\circ} \mathrm{C}$, then cooled to $-100^{\circ} \mathrm{C}$, and finally again heated to $+100^{\circ} \mathrm{C}$. Heating and cooling rates were $10^{\circ} \mathrm{C} \mathrm{min}{ }^{-1}$. DSC measurements were carried out repeatedly for all samples under these conditions and reproducible traces are shown in Figure 3.

The DSC traces in Figure 3 seem very complicated. On heating, some samples showed two discrete endothermic peaks and some only one peak. Some samples show an exothermic peak between two endothermic peaks.

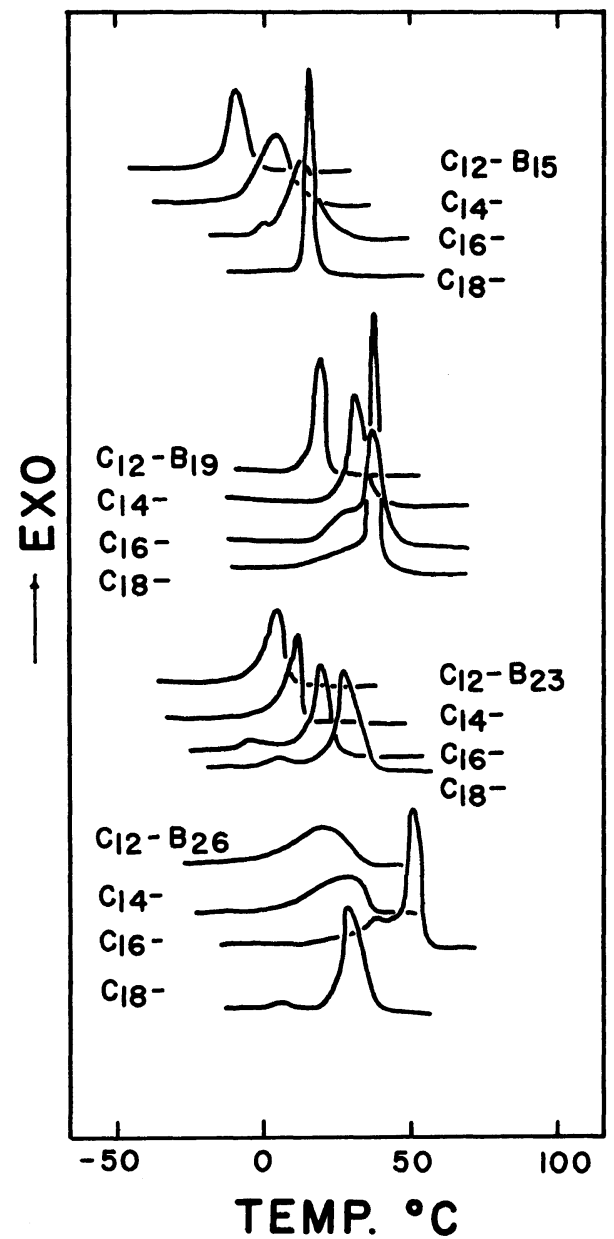

Figure 4. Cooling DSC traces for poly(2-alkyltrimethylene alkanedioates).

Such complicated DSC traces on heating determinations were observed in our first paper $^{1}$ of this series for some samples of two widely spaced comb-like polymers II and III and one conventional comb-like polymer, poly(alkyl methacrylates). Sobbotka and Sochava ${ }^{7}$ have reported the same observation for poly(alkyl vinyl ethers), poly(alkyl acrylates) as well as poly(alkyl methacrylates). They consider the two endothermic peaks as due to two different crystalline modifications. Still more complicated in the present experiments is that repeated heating peaks are generally dissimilar. Therefore again in this study, as in previous 
Table II. Side-chain crystallization of poly(2-alkyltrimethylene alkanedioates) ${ }^{\mathrm{a}}$

\begin{tabular}{|c|c|c|c|}
\hline \multirow[t]{2}{*}{ Polymer ${ }^{b}$} & \multirow{2}{*}{$\begin{array}{c}\text { Crystallization } \\
\text { temperature } \\
\frac{T_{\mathrm{c}}}{{ }^{\circ} \mathrm{C}}\end{array}$} & \multirow{2}{*}{$\begin{array}{c}\begin{array}{c}\text { Heat of } \\
\text { crystallization } \\
\Delta H_{\mathrm{c}}\end{array} \\
\begin{array}{c}\mathrm{kJ} \text { repeating } \\
\mathrm{unit}^{-1} \mathrm{~mol}^{-1}\end{array}\end{array}$} & \multirow{2}{*}{$\begin{array}{c}\text { Number of } \\
\text { crystallizing } \\
\mathrm{CH}_{2} \text { groups, } \\
N\end{array}$} \\
\hline & & & \\
\hline $\mathrm{C}_{12}-\mathrm{B}_{15}$ & -8 & 23.3 & 7.6 \\
\hline$C_{14}-B_{15}$ & 3 & 30.4 & 9.5 \\
\hline$C_{16}-B_{15}$ & 13 & 38.4 & 15.0 \\
\hline$C_{18}-B_{15}$ & 14 & 34.8 & 11.3 \\
\hline $\mathrm{C}_{12}-\mathrm{B}_{19}$ & 18 & 32.9 & 10.7 \\
\hline$C_{14}-B_{19}$ & 29 & 40.4 & 13.1 \\
\hline$C_{16}-B_{19}$ & 36 & 46.0 & 15.0 \\
\hline $\mathrm{C}_{18}-\mathrm{B}_{19}$ & 37 & 50.7 & 16.5 \\
\hline $\mathrm{C}_{12}-\mathrm{B}_{23}$ & 6 & 31.2 & 10.2 \\
\hline $\mathrm{C}_{14}-\mathrm{B}_{23}$ & 12 & 35.2 & 11.5 \\
\hline$C_{16}-B_{23}$ & 21 & 47.3 & 15.4 \\
\hline $\mathrm{C}_{18}-\mathrm{B}_{23}$ & 27 & 55.9 & 18.2 \\
\hline $\mathrm{C}_{12}-\mathrm{B}_{26}$ & 23 & 35.4 & 11.3 \\
\hline $\mathrm{C}_{14}-\mathrm{B}_{26}$ & 31 & 44.0 & 14.2 \\
\hline $\mathrm{C}_{16}-\mathrm{B}_{26}$ & 52 & 61.8 & 20.1 \\
\hline $\mathrm{C}_{18}-\mathrm{B}_{26}$ & 29 & 57.9 & 18.8 \\
\hline
\end{tabular}

${ }^{\text {a }}$ For the DSC determinations, see the text.

b For the symbol, see the text.

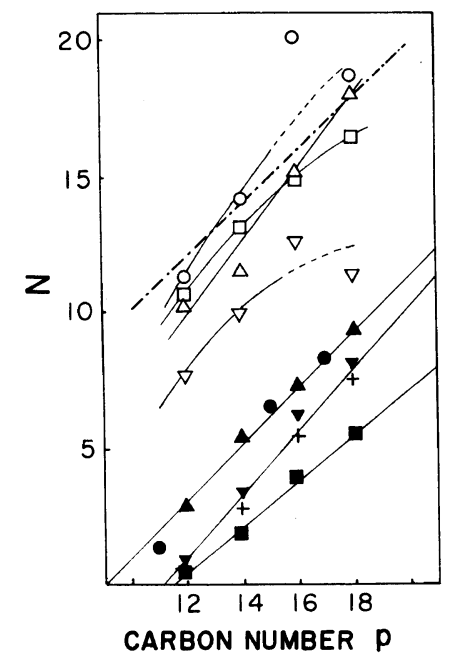

Figure 5. Plots of numbers of crystallizing $\mathrm{CH}_{2}$ groups $N$ against carbon numbers of alkyl side-chain $p$. Symbols are: $\nabla, \mathrm{C}_{n}-\mathrm{B}_{15} ; \square, \mathrm{C}_{n}-\mathrm{B}_{19} ; \triangle, \mathrm{C}_{n}-\mathrm{B}_{23} ; \bigcirc, \mathrm{C}_{n}-\mathrm{B}_{26} ;+, \mathrm{II}$; $\boldsymbol{\nabla}$, III; $\boldsymbol{\Delta}$, polyalkyl acrylates; $\boldsymbol{\square}$, polyalkyl methacrylates; and polyvinyl alkanoates. The chain line indicates $N=p$. papers, exothermic peaks occasionally with a small shoulder are discussed.

Figure 4 rearranges these cooling traces so as to compare polymers of various $p$ side-chain carbons and constant $q$ main-chain atoms. Evaluating these peaks, Table II gives crystallization temperatures $T_{\mathrm{c}}$, heats of crystallization $\Delta H_{\mathrm{c}}$, and the numbers of crystallizing $\mathrm{CH}_{2}$ groups $N . T_{\mathrm{c}}$ was taken at the peak top, $\Delta H_{\mathrm{c}}$ was calculated from the whole peak area including the shoulder if any, and $N$ was calculated by dividing $\Delta H_{\mathrm{c}}$ by $3.08 \mathrm{~kJ} \mathrm{~mol}^{-1} \mathrm{CH}_{2}{ }^{-1}$ (a reported value for hexagonal-packed $n$ -

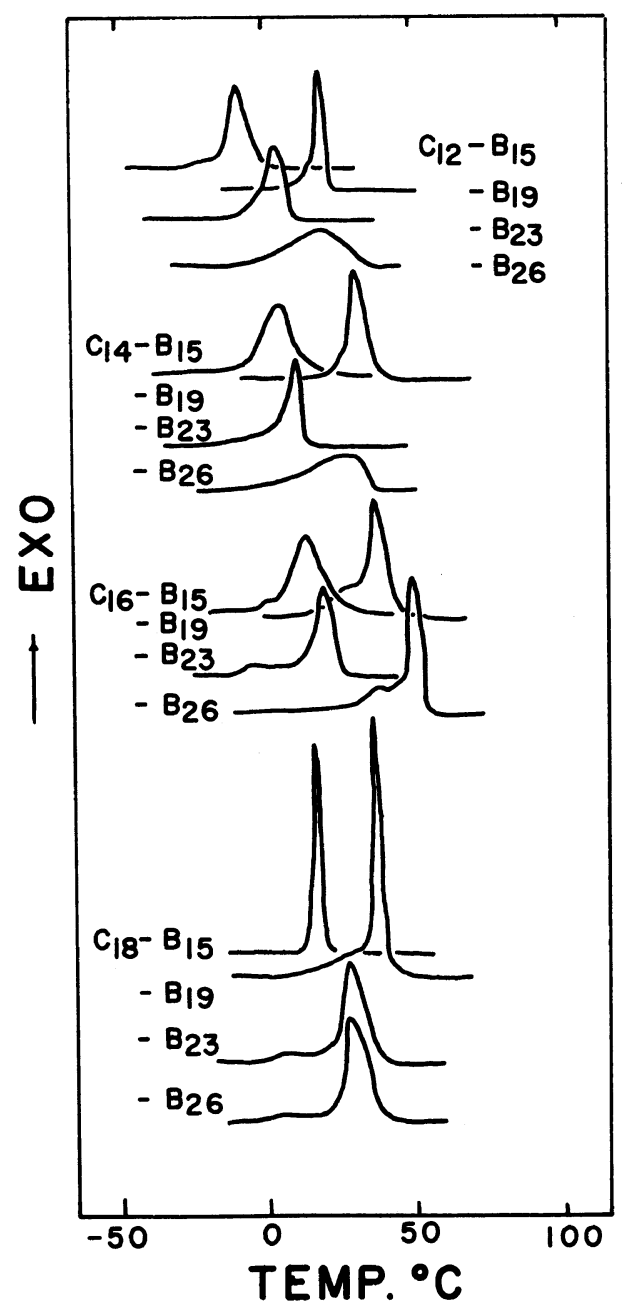

Figure 6. Cooling DSC traces for poly(2-alkyltrimethylene alkanedioates). 
alkanes $\left.^{8}\right)$.

In previous papers, ${ }^{1-3}$ the exothermic DSC peaks were considered throughout as due to the crystallization of long alkyl side-chains on the basis of extensive studies on comb-like polymers $^{9}$ and our own evidence. In Figure 4 and Table II, a general trend for comb-like polymers that $T_{\mathrm{c}}, \Delta H_{\mathrm{c}}$, and peak-shape sharpness increase with $p$ is again observed with a few exceptions. In Figure 5, $N$ numbers are plotted against $p$. There we found that $N$ numbers for the more widely spaced comb-like polymers IV in this study seem larger (about 3-7 $\mathrm{CH}_{2}$ groups) than for the two widely spaced comb-like polymers II and III $^{2}$ and for conventional comb-like polymers (for the sake of simple illustration, $N$ numbers only for polyalkyl acrylates, ${ }^{10}$ polyalkyl methacrylates, ${ }^{1}$ and polyvinyl alkanoates ${ }^{10}$ are shown). In addition, the correlation between $N$ and $p$ is poor for the present comb-like polymers when compared to the others. It should be noted that $N$ numbers for some present comb-like polymers exceed $p$, a phenomenon evidently impossible and hence strongly suggesting the participation of main-chain crystallization.

Figure 6 compares polymers of constant $p$ carbons and various $q$ atoms. It cannot be reasonably discussed on the influence of $q$ on $T_{\mathrm{c}}, \Delta H_{\mathrm{c}}$, and peak shape, but should be noted that dull peaks are observed for polymers of wider spaces.

In a previous paper, ${ }^{2}$ we referred to Batzer and Wiloth's study ${ }^{11}$ that aliphatic polyesters themselves are often crystalline solids but branched polyesters are liquid. As mentioned above in the introduction, we considered that, for widely spaced comb-like polymers with teeth appearing on every 4,6 , and 11 to 15 main-chain atoms, crystallization occur with respect to the long alkyl side-chains but not to the main-chains. The present observation, however, suggests that, when the space between teeth become wider, crystallization involves the main-chains as well as the side-chains. Detailed crystalline structure consisting of main-chains as well as side-chains needs further investigation.

Acknowledgements. The authors wish to thank Iwata Chemical Industry Co., Ltd. for the research grant.

\section{REFERENCES}

1. K. Yokota, T. Kougo, and T. Hirabayashi, Polym. J., 15, 891 (1983).

2. K. Yokota and T. Hirabayashi, Polym. J., 18, 177 (1986).

3. T. Hirabayashi, T. Kikuta, K. Kasabou, and K. Yokota, Polym. J. (in press).

4. S. Hünig, E. Lücke, and W. Brenninger, Organic Syntheses, Coll. Vol., 5, 808 (1973).

5. S. Hünig, E. Lücke, and W. Brenninger, Chem. Ber., 91, 129 (1958).

6. Beilsteins Handbuch der Organischen Chemie.

7. I. Sobbotka and I. V. Sochava, Vysokomol. Soedin., Ser. A, 21, 1322 (1979).

8. M. G. Broadhurst, J. Res. Natl. Bur. Stand., 66A, 241 (1962).

9. N. A. Platé and V. P. Shibaev, J. Polym. Sci., Macromol. Rev., 8, 117 (1974).

10. E. F. Jordan, Jr., D. W. Feldeisen, and A. N. Wrigley, J. Polym. Sci., A-1, 9, 3349 (1971).

11. H. Batzer and F. Wiloth, Makromol. Chem., 6, 60 (1951). 